\title{
RADUAN NASSAR: ENTRE O SILÊNCIO E O POÉTICO
}

Edner Morelli*

Resumo: O objetivo desse artigo consiste em tecer considerações sobre o escritor Raduan Nassar, a fim de apresentar algumas de suas ideias sobre a Literatura e o fazer literário. A figura do escritor, paulista de Pindorama, é emblemática no cenário literário contemporâneo. Inusitada por dois motivos: primeiro, pela qualidade estético-artística de sua "reduzida" obra (três livros ao todo); segundo, pelo fato de desistir do ofício de escrever, preferindo a vida rural ao palco vaidoso e sedutor da academia.

Palavras-chave: Raduan Nassar, poética, fazer literário, prosa.

Abstract: The purpose of this article is to consider the writer Raduan Nassar in order to present some of his ideas about literature and literary work. The figure of the writer, Pindorama, from São Paulo, is emblematic in the contemporary literary scene. Unprecedented for two reasons: first, for the aesthetic-artistic quality of its "reduced" work (three books in all); Second, by giving up the office of writing, preferring rural life to the vanity and seductive stage of the academy.

Keywords: Raduan Nassar, poetics, literary making, prose.

Destarte, sem muitos subterfúgios, Raduan Nassar, ao ser questionado sobre sua atual condição social e sua práxis diária, assim se manifestou:

Hoje minha vida é fazer, fazer, fazer, no âmbito da fazenda evidentemente, num espaço em constante transformação, o que não deixa de ser uma outra forma de escrever. Além disso, tem em comum com a literatura o fato de eu não saber por quê. Então é fazer, fazer. (NASSAR, 1996, p.39)

Irresistível não lembrar da poiesis grega, em que o fabricar e o agir também eram considerados uma forma de poesia. Esse espaço natural em "constante transformação", entendemos também como um terreno de grandes oscilações, pois a natureza possui essa característica básica de nos proporcionar instantes de remanso e outros de intensa fúria (hybris), movimento esse semelhante à própria configuração de Lavoura Arcaica, por

\footnotetext{
* Mestre em Literatura pela PUC-SP; Professor da FAINAM-SBC.
} 
exemplo. Quem teve contato com a obra se lembrará das oscilações temporais entre o tempo presente e o da memória do narrador, até as mudanças comportamentais das personagens, potencializando uma pluralidade de sentidos para a obra.

Com relação ao cotidiano de Raduan Nassar, destacamos uma observação de Bonvicino e Carvalho publicada no jornal Folha de S. Paulo:

\begin{abstract}
Não é como Rimbaud (1854-1891), que abandonou a literatura ainda adolescente para traficar armas e escravos no norte da África. Aos 53 anos, Raduan dedica-se atualmente a cultivar 15 alqueires de arroz irrigado, na sua fazenda em Buri, 270 $\mathrm{km}$ a sudeste de São Paulo. Cria também vacas, ovelhas, gansos, marrecos e galinhas, Não é reconhecido como escritor pelos que convivem com ele no seu diaa-dia rural. (1989, p. E1)
\end{abstract}

Nascido em 27 de novembro de 1935, descendente de libaneses, Nassar possui uma relação com a literatura, no mínimo, um tanto inusitada, na medida em que encontramos em sua trajetória artística uma linha que percorre os pólos da paixão e da aversão pelo mundo literário. Não é intenção aprofundarmos detalhes biográficos que levariam a especulações desnecessárias. Recorremos apenas a depoimentos do próprio Raduan e, por vezes, de alguns críticos, no intuito de trazer para o leitor um perfil crítico do autor.

O envolvimento de Raduan Nassar com a Literatura teve início em sua adolescência. Influenciado pela irmã Rosa (professora de português), começou, por volta de 1951, a fazer leitura de alguns clássicos brasileiros. Mas foi, sem dúvida, por meio de algumas figuras do curso de Direito do Largo de São Francisco que a consciência literária de Nassar tomou fôlego e adquiriu forma crítica.

Nassar frequentou, sem concluir, o Curso de Direito até o último ano (1959); cursou ao mesmo tempo Letras, mas abandonou rapidamente (1955). É formado apenas em Filosofia (USP-1963). Foram seus contemporâneos, do Curso de Direito, personalidades de destaque no mundo das Letras como Modesto Carone, Hamilton Trevisan e o jornalista e escritor José Carlos Abatte. Esse último, em depoimento para os Cadernos de Literatura Brasileira, assim se manifestou:

De 1957 a 1961, um grupo restrito de jovens entre 20 e 24 anos trocava idéias no pátio da Faculdade de Direito do largo de São Francisco nos intervalos ou no fim das aulas do curso noturno. Menos que ciências jurídicas, o assunto era literatura, vida, preferências intelectuais. Alguma coisa nos dizia que o grande escritor daquele grupo era o Raduan, o mais taciturno de todos, cujos silêncios prolongados nos pareciam opressivos. Trocávamos fragmentos de textos, esboços de narrativas; em um deles, do Raduan, atentei para a quebra dos hábitos da linguagem convencional. Aqui tem o dedo de um bom escritor, me disse Hamilton Trevisan, 
confirmando a impressão que me haviam provocado as metáforas arrojadas. Apenas o Modesto Carone, cuja acuidade crítica já era então notável, e o Raduan pareciam possuir consciência da noção de escritura e do texto como problema estético na ficção. Nos intervalos de seus silêncios, o Raduan falava sempre no "nível de execução", frase que me soava quase como emblema. (1996, p. 16)

Esse grupo, como o trecho destaca, estava mais preocupado com a Literatura e suas discussões subjetivas do que propriamente com a objetividade do mundo jurídico. Raduan se destacava por possuir a "consciência da noção de escritura e do texto como problema estético na ficção". Nitidamente, em suas obras, encontramos o trabalho intenso com a palavra, uma preocupação estrita com o "nível de execução" textual, ou seja, a ideia de se empenhar na busca das melhores estruturas semântico-estéticas capazes de mimetizar a vida em sua essência mais artística.

A produção literária de Raduan Nassar origina-se nas décadas de 60-70. O primeiro livro, o romance Lavoura Arcaica, é de 1975, editado pela José Olympio, com reedições pela Nova Fronteira (1982) e Companhia das Letras (1989). Segue a novela Um Copo de Cólera de 1978, editado pela Cultura, com reedições pela Brasiliense (1984) e Companhia das Letras (1992). Por último, um livro de contos, cujo título é Menina a caminho, editado pela Companhia das Letras (1994), numa edição não-comercial, por propósito da comemoração dos 500 títulos da editora. Essa reunião de contos também ganhou uma edição comercial da própria Companhia das Letras, com o título Menina a caminho e outros textos (1997).

Raduan Nassar manteve uma relação curiosamente curta e intensa com a vida literária. Quando indagado sobre esse fenômeno de "dedicar-se inteiramente numa época (à literatura), renunciando a tudo em nome dela, e depois parar de escrever” (NASSAR, 1996, p.16), o autor afirma: "Foi a paixão pela literatura, que certamente tem a ver com uma história pessoal. Como começa essa paixão e por que acaba, não sei” (ibidem, p. 24).

Essa afirmação incita a pensarmos numa relação entre Raduan e a literatura envolvendo a própria pathos humana, ou seja, as relações passionais possuem mesmo esse caráter de intensidade máxima, seguida, quase sempre, de um resfriamento sem explicações aparentes. Oscilações próprias de um cosmo caótico e infinito.

$\mathrm{Na}$ verdade, o escritor passou longe de esboçar um grande projeto literário. O plano essencial de Nassar era escrever. "Dei conta de repente de que gostava de palavras, de que queria mexer com as palavras. Não só com a casca delas, mas com a gema também. Achava que isso bastava" (ibidem, p. 24). Podemos inferir por essas duas metáforas sobre a palavra "casca" e "gema", que Raduan tinha a pretensão de trabalhar o significante (a casca), mas nunca se esquecendo do potencial semântico dos vocábulos (a gema), pois como ele mesmo 
diz "era um trânsito de duas mãos, uma relação dinâmica entre os dois níveis" (NASSAR, 1996, p. 24).

A intenção manifestada por Nassar era apenas de escrever, não se filiando a qualquer movimento estético em voga, nem se envolvendo com questões teóricas discutidas em manifestos. Fica nítida, pelo estilo nassariano, a consciência estética do escritor, ao evidenciar que o fazer literário é sempre uma luta entre a palavra, o discurso, o escritor e a vida.

Cabe ressaltar que na época da formação literária de Nassar, anos 50-60, estavam em voga as teorias da Poesia Concreta e a ideia de produzir uma literatura antidiscursiva e antilírica. Curiosamente, certos críticos já insinuaram uma ligação entre Nassar e os Concretos, talvez pela sua preocupação visível com o lado material das palavras (sons, ritmos etc.). Indagado se essa aproximação o irritava, o escritor diz: "De modo algum, são boas praças, só que já estariam em outra hoje. Resta saber também se eles conseguiriam engolir um paralelepípedo lírico como eu" (ibidem, p. 35-36).

Uma das essências da obra nassariana é o potencial lírico de sua narrativa. Aproximando-se de uma prosa poética, Nassar produz textos condensados em que uma voz central (do narrador) reclama os próprios estados de alma, num ritmo sugestivo e poético: "acredito que a boa prosa tenha sido sempre poética. Porque existe também a arte que se constrói com significados e que se nutre no mundo inesgotável da semântica” (ibidem, p. 25).

Raduan acredita no poder da relação entre as palavras e suas potencialidades semânticas. Dentro de uma perspectiva nassariana, a literatura é o espaço das infinitas possibilidades de significado que um vocábulo pode desferir. Convém transcrever mais uma fala do escritor, ao se referir à estética antidiscursiva vigente no período de sua formação literária e à escolha por um caminho diverso:

\footnotetext{
Acho que não adianta forjar uma escolha metafísica para aquela postura, como arrolar a estética disso ou a estética daquilo, porque no fundo o caso daquela tendência seria mesmo a inaptidão pra reflexão existencial. Agora, a casca das palavras, da proposta antidiscursiva, como a laranja que se passa num espremedor, certamente que não excluía resíduos de significados. Fosse então o caso de forjar uma escora, quando muito se poderia falar na estética do bagaço. Não vai aí qualquer conotação pejorativa, é só uma tentativa de adequação vocabular. Entre usar bagaço ou palavras em toda sua acepção possível, cada escritor que fizesse a sua escolha. (NASSAR, 1996, p. 24)
}

Como é possível observar, Nassar deixa claro que sua opção foi usar as palavras em todas as suas "acepções possíveis"; a saber, usar apenas o bagaço ou a casca das palavras 
limitaria sua criação literária. Não é intenção aqui desmembrar teoricamente a proposta da poesia concreta e seu antilirismo ou antidiscursividade; essa explanação coube apenas para mostrar a opção de Raduan por um outro caminho, ou seja, a produção de uma prosa poética, pautada sempre num lirismo visceral, sem nenhum vínculo aparente com as tendências em voga. Cabe ressaltar também que nos anos 70, época fecunda da criação nassariana, produziase também uma literatura engajada, panfletária, contra a ditadura militar. Nassar também não aderiu a esse caminho. Milton Hatoum assim se manifestou sobre esse aspecto:

Li Lavoura Arcaica em 1976, numa época em que muitos livros de ficção pretendiam denunciar a brutalidade da vida política brasileira. Para a nossa literatura, os anos 70 não foram uma década perdida; basta lembrar que, nessa época, Osman Lins e Clarice Lispector publicaram obras-primas como Avalovara e A hora da estrela. Mas o toque militar de recolher parecia impor um tema a alguns escritores que queriam escrever sobre o tempo presente, esse tempo que, para a literatura, parece ser um contratempo. Lavoura Arcaica fugia do factual, do circunstancial, e aderia a algo que penso ser importante numa obra literária: a linguagem, muito elaborada, que invoca um conteúdo de verdade, uma dimensão humana, profunda e complexa. (1996, p. 20)

Raduan também acredita que toda forma de imposição feita para um escritor seguir esta ou aquela tendência literária é deveras perigosa, pois a conjunção, entre o escritor e seu estilo, passa por tais impressões:

Os caminhos, segundo Raduan, são infinitos, os indivíduos têm histórias pessoais,
são diferentes entre si e, pelo menos na literatura, cada um deveria fazer suas
próprias escolhas. Sem falar que o milagre pode acontecer em qualquer direção,
mas definitivamente não acontece se houver uma ruptura entre a sensibilidade de
um autor e o que ele venha a produzir, a pretexto de seguir a modernidade apontada
por terceiros [...]. (CARVALHO e BONVICINO, 1989, p. E1)

Esse trecho é elucidativo e serve como uma espécie de síntese do que Raduan acredita ser a relação mais sincera entre o autor e sua obra. Segundo Nassar, nunca pode haver "uma ruptura entre a sensibilidade de um autor e o que ele venha a produzir", a serviço de qualquer tendência literária vigente. A obra do escritor é um espelho de suas escolhas pessoais, portanto, "os caminhos são infinitos", mesmo porque, cada experiência vivida possui um grau de exclusividade de sentimentos e sensações deflagradas apenas por quem as vive.

Essa associação entre os caminhos pessoais de um escritor e a feição de sua obra acreditamos ter ligação com a concepção nassariana de Literatura. Numa entrevista a Arnaldo 
Jabor, para a Folha de São Paulo, num momento colérico de desabafo, misto de raiva e cansaço por todo e qualquer hermetismo e tendências impostas, Nassar explode:

E que diabos, a literatura sem vínculos profundos com a vida não é nada! E ficam estas escolinhas lambendo o saco de Joyce e de Pound! E que diabo, ninguém tem coragem de dizer que não aguenta "Finnegans Wake", e que Pound tem doze poemas bons! E eu não consigo ler Oswald de Andrade e esta divisão Mário versus Oswald já existe há trinta séculos! E eu tenho coragem de dizer que não li Guimarães Rosa pra me proteger, pois ele não é da minha praia, e, puta que pariu, fiz meus dois textinhos sem levar em conta a zoeira aí fora, fiz lirismo quando o lirismo estava fora de moda [...] e demônios! A pretexto de seguir a modernidade, os escritores acabam por bloquear o seu talento específico e [...] cacete!, ficam obedecendo os teóricos e as regrinhas! E a liberdade é uma das poucas coisinhas boas que a vida nos dá, e sem a experiência vivida a literatura não é nada e toda concepção literária não é maior que a vida! (1992, p. 5-9)

Como vemos, Nassar traça um binômio indispensável entre a Literatura e a vida, pois “a literatura sem vínculos com a vida não é nada”. A principal matéria-prima do escritor é a própria vida. Como ele mesmo disse ao crítico Davi Arrigucci Junior, ao indagá-lo sobre suas influências literárias, "a leitura que eu mais procurava fazer era do livrão que todos temos diante dos olhos". (NASSAR, 1996, p. 27).

Outro aspecto da biografia de Raduan que convém destacar é a ligação dele com o jornalismo. O escritor fundou, em 1967, junto com os irmãos, o semanário "Jornal do bairro", em que ele exercia a função de diretor. O jornal, apesar de regional, chegou à tiragem de 160.000 exemplares por edição. Em 1974, Nassar desliga-se do jornal por não aceitar algumas mudanças editoriais. Sobre o conteúdo do jornal, comenta:

\begin{abstract}
Além do noticiário regional, que cobria boa parte da zona oeste de São Paulo, o jornal abria espaço para matérias nacionais e internacionais. Fazia oposição ao regime da época e identificava-se com as reivindicações do então Terceiro Mundo. Dava atenção também aos grupos minoritários. E se esforçava no exercício crítico, tanto que algumas iniciativas do regime militar que iam ao encontro das posições do Terceiro Mundo mereceram registros adequados. Como de resto as primeiras posições políticas da igreja. (1996, p. 25)
\end{abstract}

Com relação à passagem de Raduan pelo jornal e a experiência que ele obteve com a sua linguagem e com o próprio desenvolvimento da comunicação, decididamente, a escrita jornalística o ajudou em certos aspectos, assim como obter contato com a palavra impressa. Assim comenta o escritor:

Eu era um sujeito muito trancado e as condições de trabalho na redação me levaram a falar mais do que estava habituado. Antes, eu tinha uma linguagem oral 
desenvolta, mas só entre uns poucos amigos. Na redação, pelo menos, acabei virando um pouco gente. Agora, do ponto de vista da escrita, a redação me impôs certo rigor de procedimento. Uma coisa era a palavra numa lauda, outra coisa era a mesma palavra já impressa. Havia uma mudança de qualidade. Coisas assim me levaram, como responsável pelo jornal e redator, a uma leitura mais atenta aos textos, era preciso pesar cada palavra, ainda que tivéssemos cometido besteiras. $\mathrm{O}$ jornal destrancou parte da minha timidez, mas me destrancou muito mais como escritor. (1996, p. 25-26)

Em certa medida, a experiência de Raduan com o jornal desencadeou um processo benéfico para sua própria comunicação: “acabei virando um pouco gente”. Mas o que interessa ressaltar aqui é a postura crítica com a palavra que Nassar adquiriu nessa experiência jornalística de redator. A responsabilidade da "palavra impressa" fez com que o escritor "pesasse cada uma delas", desenvolvendo uma relação, senão estética, ao menos, consciente do poder que cada vocábulo detém em determinado contexto.

A literatura para Raduan Nassar, portanto, dialoga com a vida. Se uma obra não contiver pulsões geradoras de sentidos e sentimentos humanos, não sustenta o porquê de sua existência. Com relação ao seu silêncio, não há motivos aparentes que tivessem gerado a sua prostração diante do literário, mas podemos fazer algumas conjecturas a respeito desse silêncio, associando-o à concepção que o escritor tem da espécie humana:

Eu não morro de amores pela espécie [...] eu acho que o homem é uma obra acabada. Pode estar diferente hoje, adquirir conhecimento, criar as maquininhas, voar pelo espaço, mas eu acho que ele é uma obra acabada. Eu não aposto no aprimoramento da espécie, eu não aposto nisso. Isso talvez tenha até a ver com meu desinteresse pela literatura de um modo geral. E aí talvez minha náusea em torno de toda produção cultural, eu não aposto muito nisso, se o objetivo é achar que a espécie vai melhorar com isso. (NASSAR, 1995, p. E2 )

O fato é que o desinteresse do escritor para com a Literatura tem a ver com o seu pessimismo em relação ao ser humano. Nassar não acredita em mudanças essenciais para a espécie, e nem acredita que a arte, de um modo geral, possa trazer o "aprimoramento dessa espécie”. Numa postura crítica e excessivamente pessimista, o homem, para o escritor, é uma "obra acabada", sem perspectiva de aperfeiçoamento essencial.

O abandono da literatura é, em Raduan Nassar, o desnudamento radical. Esse abandono é o efeito de uma cólera, com tudo o que a cólera implica de expectativas frustradas. O tamanho da cólera e o silêncio casmurro que sucede ao acesso dão a medida exata de tudo o que o escritor espera do mundo e da literatura [...]. (PERRONE MOISÉS, 1996, p. 76) 
O silêncio "radical" de Raduan é, antes de tudo, para com o mundo, ou melhor, para com o ser humano de uma forma geral. Esse silêncio transpassa o âmbito do literário e penetra nas próprias opções pessoais do escritor. Nassar produziu uma literatura cuja escrita possui uma "força e uma densidade raramente encontradas na Literatura Brasileira" (PERRONE-MOISÉS, 1996, p. 61), um discurso permeado de cólera. Essa "força colérica" silenciou-se na praxis literária, contudo, a cada leitura de sua obra, o discurso se faz vivo novamente, com a mesma intensidade mimetizadora que a arte proporciona, além do mais, na opinião de Cordiviola, existem escritores que

\footnotetext{
sugerem que uma obra completa não exige muitos volumes para estar completa, e que a multiplicação não é apenas inútil, mas também irrisória. [...] Talvez seja mais prudente multiplicar os silêncios do que multiplicar as páginas, pois há um espectro que ronda o ofício de escrever: aquele que sussurra ao ouvido que o futuro não reserva nada melhor, porque quiçá o melhor já foi feito. (2002, p. 13)
}

Essa elucidativa observação do crítico, ao se referir a Nassar, sintetiza a passagem do escritor pelo mundo literário. Existem alguns que possuem uma aura mítica capaz de "multiplicar os silêncios", insinuando que nem sempre um grande escritor precisa possuir uma obra extensa, (haja vista Graciliano Ramos) visto que há a possibilidade de que o "melhor já foi feito", e toda produção posterior passaria a ser inútil e irrisória, nunca atingindo a grandiosidade das páginas pretéritas.

Não medimos a grandeza de um escritor pela quantidade de páginas impressas, mas pela intensidade estética que cada uma delas proporciona. Nesse caso, sem dúvida, Raduan Nassar sempre estará entre os grandes literatos de nossa esfera literária. E mal comparando, há quem diga que uma grande banda de Rock sempre deveria parar no terceiro álbum.

\section{Referências bibliográficas}

BONVICINO, Régis; CARVALHO, Mario Cesar. O fazendeiro Raduan quer ser best-seller.

Folha de São Paulo, 18 de março de 1989, p. E1.

CORDIVIOLA, Alfredo. Prefácio. In: Uma lavoura de insuspeitos frutos. São Paulo:

Annablume, 2002.

HATOUM, Milton. Cadernos de Literatura Brasileira, n. 02. São Paulo: Instituto Moreira Sales, 1996.

NASSAR, RADUAN. Cadernos de Literatura Brasileira. n. 02. São Paulo: Instituto Moreira Sales, 1996. 
. Entrevista cedida a Arnaldo Jabor à Folha de São Paulo, 19 de abril de 1992.

. Entrevista cedida à Folha de São Paulo, 03 de maio de 1995.

PERRONE-MOISÉS, Leyla. Da cólera ao silêncio. In: Cadernos de Literatura Brasileira, n.

02. São Paulo: Instituto Moreira Sales, 1996. 